\title{
Application of Air Bearings to an Electrodynamic Vibration Standard
}

\author{
T. Dimoff and B. F. Payne \\ (July 3, 1963)
}

\begin{abstract}
In an attempt to eliminate unwanted resonances and transverse motions in an electrodynamic exciter used as a vibration standard, the mechanical suspension-guide for the moving element was replaced with air bearings. The transverse motions of this exciter showed a distinct improvement over the transverse motions of the exciters with flexure plate and tensioned wire supports. The improved stability of the moving element of the air-bearing exciter made it possible to calibrate this exciter easily by an interferometer method. Agreement between three methods of calibration, reciprocity, interferometer, and optical target, was very good. The results of calibrations of two types of pickups on this modified standard are presented.
\end{abstract}

\section{Introduction}

The widespread use of vibration pickups to measure the amplitudes and frequencies of vibrations present in aircraft, rocket engines, ordnance systems, machinery, ships, etc., has led to the need for improved vibration standards. The feasibility of using certain kinds of electrodynamic vibration exciters as standards for the calibration of pickups was demonstrated by Levy and Bouche $[1,2]^{1}$. A limitation in the use of electrodynamic vibration exciters as calibrators has been the presence of undesirable transverse motions superimposed on the required sinusoidal axial motion of the moving element.

The present report describes the modifications made in a commercial electrodynamic exciter in which the mechanical suspension-guide for the moving element is replaced with air bearings. The methods used and the results of the calibration of this exciter are given and compared with exciters using flexure plate and tensioned wire supports. The results of calibrations of two types of vibration pickups using this exciter are also presented.

\section{Description of the Electrodynamic Exciter}

A rectilinear vibration exciter of the electrodynamic type was equipped with air-bearing support guides. The moving element includes a velocity sensing coil which, when calibrated, permits the exciter to be used as an electrodynamic vibration standard. The exciter is shown schematically in figure 1 . The moving element consists of a mounting table, $T$, a velocity sensing coil, $C_{2}$, a driving coil, $C_{1}$, and a connecting shaft. The table is set in motion by applying alternating current to the driving coil which is in a steady magnetic field induced by the main magnet, $M$, when direct current is passed through the field coil, $C_{m}$. The motion of the table, $T$, is measured by the voltage output of the velocity sensing coil, $\dot{C}_{2}$, in conjunction with the

\footnotetext{
${ }_{1}$ Figures in brackets indicate the literature references at the end of this paper
}

permanent magnet, $M_{2}$ since this voltage is proportional to the absolute velocity of the table motion. The pickup to be calibrated is rigidly mounted on the table, $T$.

The ideal exciter should produce pure axial motion free of transverse motions. The earlier use of flexural plates or suspension wires caused unwanted resonances and transverse motions.

More detailed discussions of the principles of operation and limitations of the electromechanical system are given in references [1, 2, and 3].

\subsection{Air-Bearing Standard}

The vibration exciter modified with an air-bearing suspension guidance system is shown in figure 1 . The moving element is supported on two air bearings of the external pressure or hydrostatic type [4-7].

The only mechanical connections between the moving element and the stationary parts of the exciter are the flexible input wire to the driver coil and the thin output wire from the velocity sensing coil. The air bearings are located in the approximate position of the replaced flexure plates. Two different sizes of bearings are used. The front bearing is 2.187 in. in diameter and the back bearing $1.250 \mathrm{in}$. The lengths of the bearings are $1.000 \mathrm{in}$. The journal of the front bearing is also the vibration table of the exciter and was designed with a larger diameter to make it possible to mount large or small vibration pickups on it. The front bearing, shown in figure 2 , has twelve orifices; the back bearing has six. The bearing sleeves have air distribution annuli 0.125 in. deep and 0.255 in. wide in their outer surface. Orifices of $0.02 \mathrm{in}$. diam. are drilled through these sleeves. The bearings have a radial clearance of $0.001 \mathrm{in}$. The bearings are made of brass and have aluminum journals.

The front bearing fixture, which is bolted down on three studs, is a $1 \mathrm{in}$. thick circular aluminum plate 14 in. in diameter. The back bearing is fixed in the same manner on the magnetic shield which is a circular steel plate $1 / 2$ in. thick and 8 in. in diameter. 


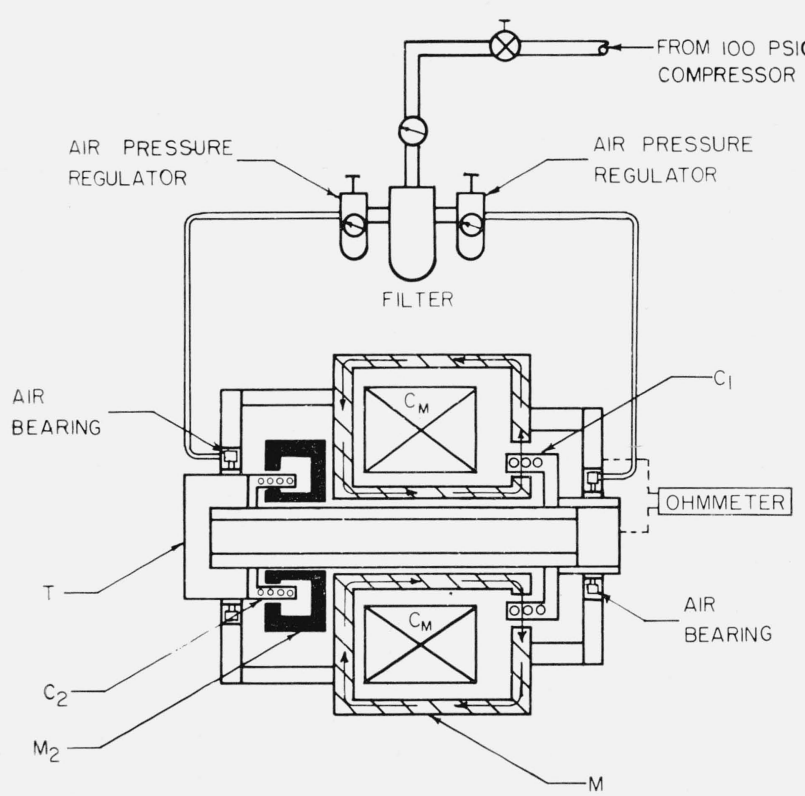

Figure 1. Schematic of electrodynamic-vibration exciter equipped with air-bearing suspension-guidance system.

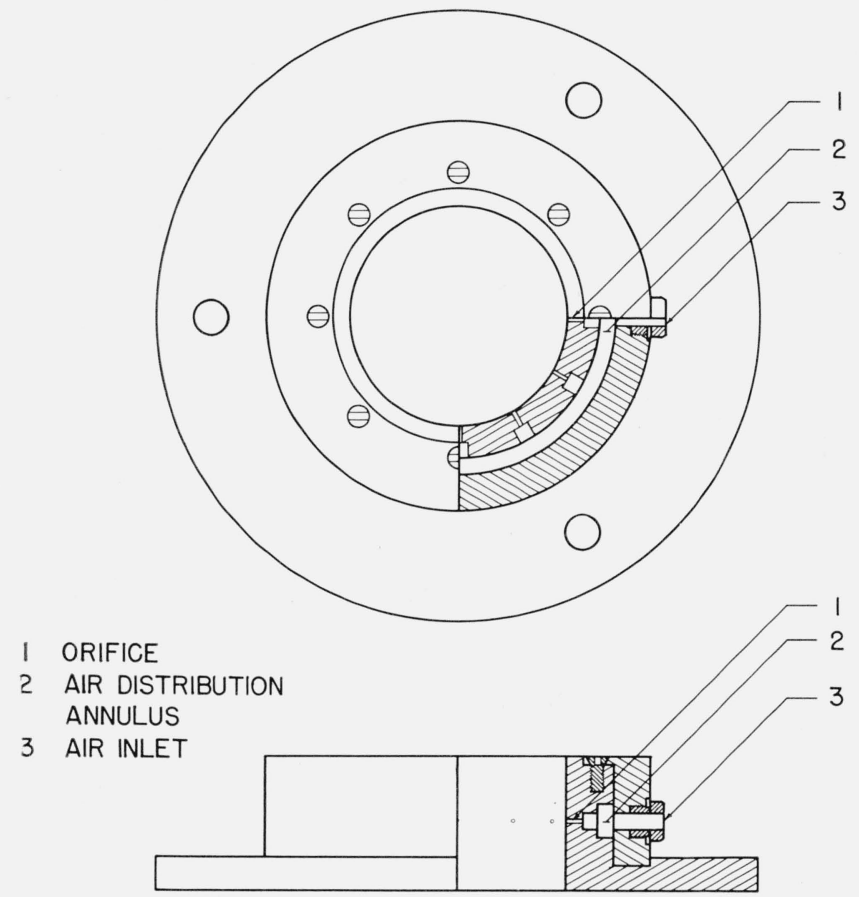

Figure 2. Air bearing used to provide one degree of freedom in the electrodynamic exciter.

The velocity coil was modified by cutting off the reduced diameter front part. It then was screwed and cemented rigidly to the table and the shaft.

The compressed air used is the building maintenance air supply. The air is filtered and each bearing has a separate air regulator (see fig. 1). The air is transmitted to the bearings by means of flexible tubing with an inside diameter of 0.125 in. During the calibration of the exciter and the pickups, the air pressure was maintained at $50 \mathrm{psig}$ for both bearings

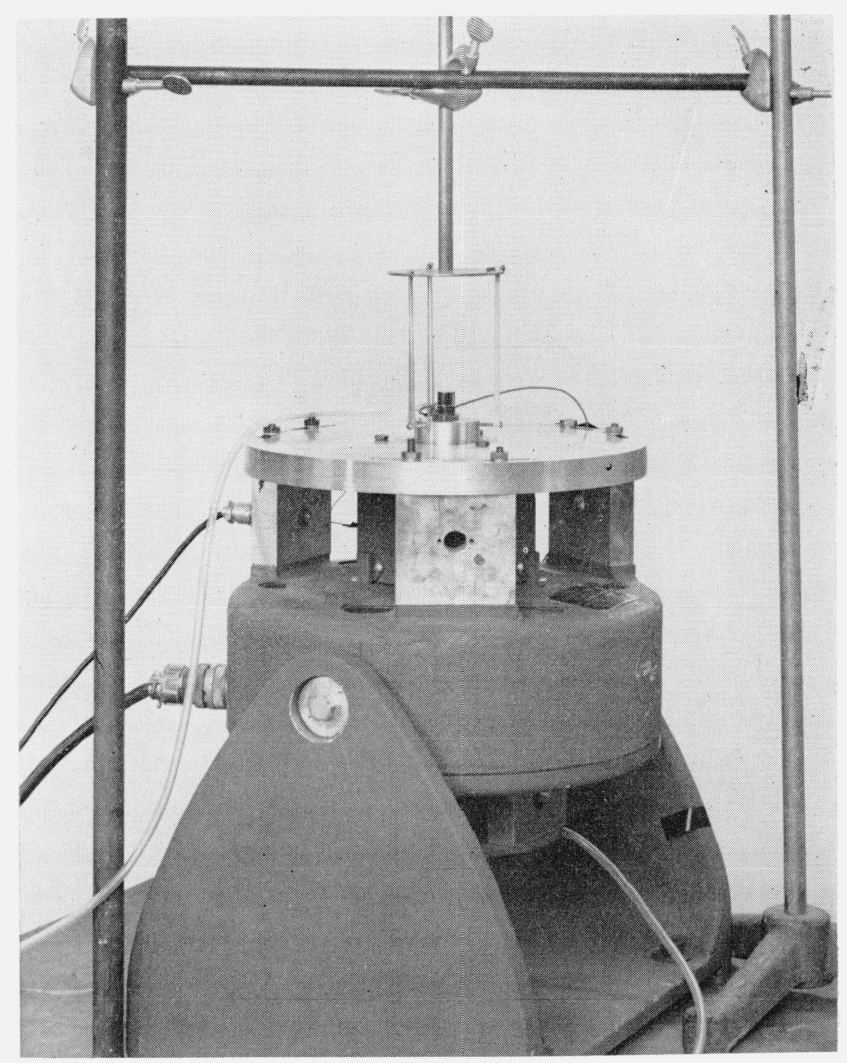

Figure 3. Setup for calibration of a piezoelectric accelerometer.

and the air temperature was about $65^{\circ} \mathrm{F}$. When varying the air pressure between 20 and 80 psig, no significant change is observed in the measured transverse motions.

When the exciter is used in a vertical position, the moving element is supported by three rubber bands $120^{\circ}$ apart attached to the moving shaft by screws and to a circular plate positioned directly above the moving element as shown in figure 3 . The circular plate can be rotated and the position of the moving element thus adjusted with respect to the stationary exciter. The equilibrium positions of the coils are held constant with respect to the magnets. With the exciter in a horizontal position, there is no need for any additional support. The leads from the driver coil provide sufficient support to keep the moving element from rotating and coming into physical contact with the stationary part of the exciter. An ohmmeter is connected between the moving element and the sleeve to indicate if metal to metal contact is made between the moving and nonmoving parts of the exciter. By careful alinement of the two bearings, this possibility is eliminated because the surfaces are always separated by a thin film of air. Having the exciter in a horizontal position with a $5 \mathrm{lb}$ weight mounted on the table, and air pressure at $20 \mathrm{psig}$, no mechanical connection is observed. A 5 psig air pressure is adequate to support the moving element with no load at tached. The performance data of the air bearing standard are given in table 1. 
TABle 1. Performance data for air-bearing exciter

\begin{tabular}{|c|c|}
\hline $\begin{array}{l}\text { Weight of moving element } \\
\text { Exciter table load } \\
\text { Force rating } \\
\text { Pounds per ampere } \\
\text { Maximum table excursion } \\
\text { Frequency of major resonance } \\
\text { Frequency of magnet structure resonance } \\
\text { D-c field resistance } \\
\text { Driver coil resistance } \\
\text { Stray magnetic field at table level }\end{array}$ & 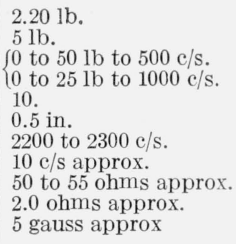 \\
\hline
\end{tabular}

\subsection{Transverse Motion Measurements}

The transverse motions of the mounting table were measured using two piezoelectric accelerometers with their principal sensitive axes mutually perpendicular to each other as shown in figure 4 [2]. The one accelerometer, which measured vertical transverse motion, has its sensitive axis perpendicular to the axial motion of the table and measures motion up and down in the plane of the page. The second accelerometer, with a sensitive axis perpendicular to the axial motion and perpendicular to the plane of the page measured the transverse motion in the horizontal direction. A third accelerometer was mounted with its sensitive axis coaxial to the axial motion of the standard to measure the axial motion or axial acceleration. The three accelerometers were mounted on a small cube of stainless steel with two dummy accelerometers to balance the load of the vertical and horizontal accelerometers.

The transverse motions indicated with these devices should not be attributed entirely to the standard since the accelerometers themselves have a transverse response. The transverse motions of the air-bearing exciter depend to a great extent on the bearing alinement and bearing clearance.

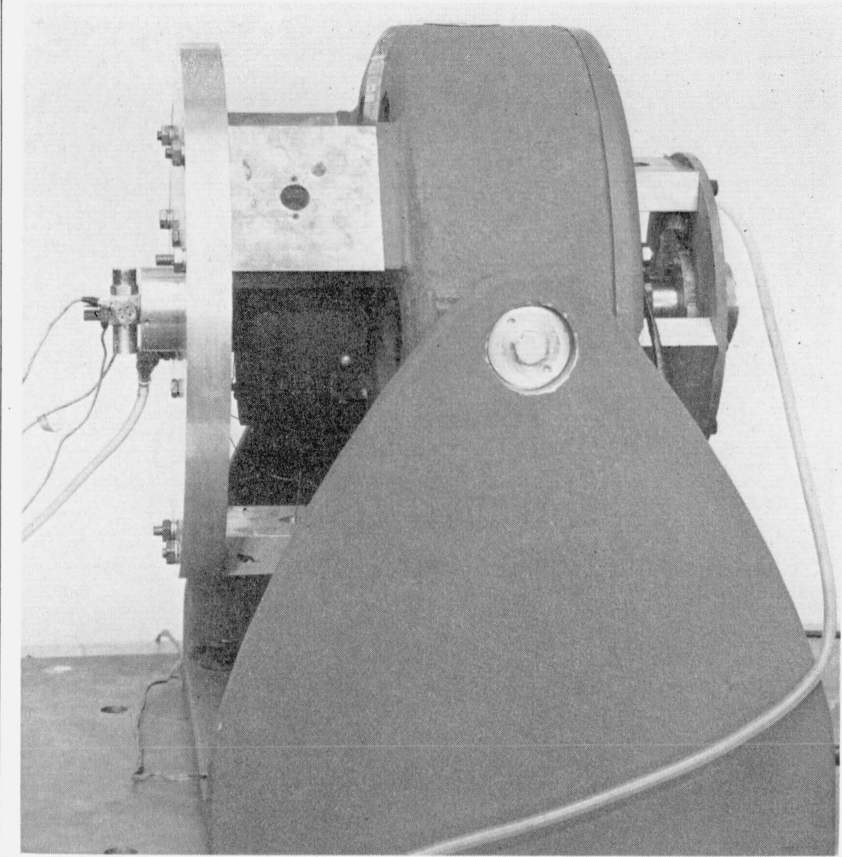

FiguRE 4. Setup for measuring transverse motion with three piezoelectric accelerometers with their principle sensitive axes mutually perpendicular.

Figure 5 shows the transverse motions of an airbearing exciter using two experimental bearings with equal diameters but with closer radial clearances (less than 0.001 in.) than the bearings subsequently installed. Significant transverse motions in the vertical direction are observed in the regions of 750 and $2,190 \mathrm{c} / \mathrm{s}$, and in the horizontal direction in the regions of 400 and $2,190 \mathrm{c} / \mathrm{s}$. The transverse motions near 400 and $750 \mathrm{c} / \mathrm{s}$ are attributed to the

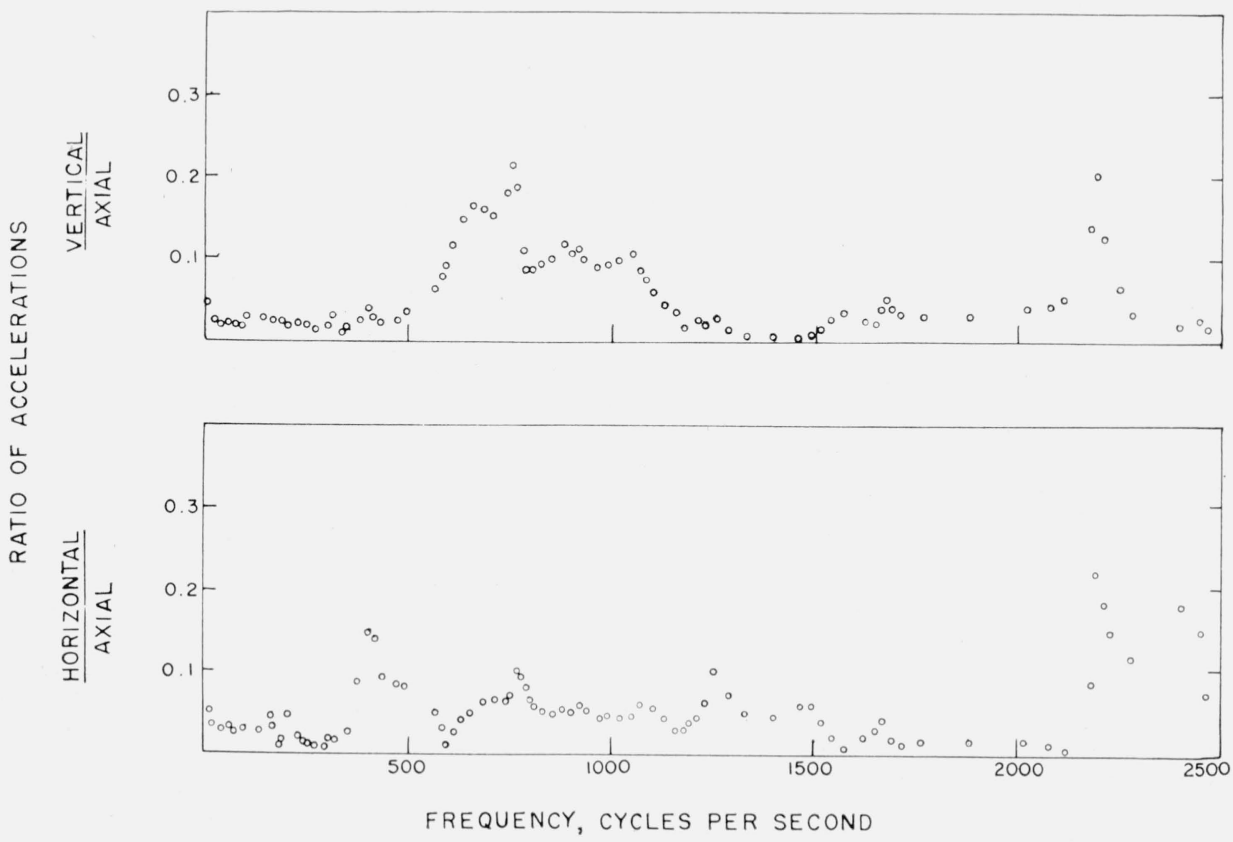

FIgURE 5. Ratios of transverse to axial acceleration using experimental air bearings. 


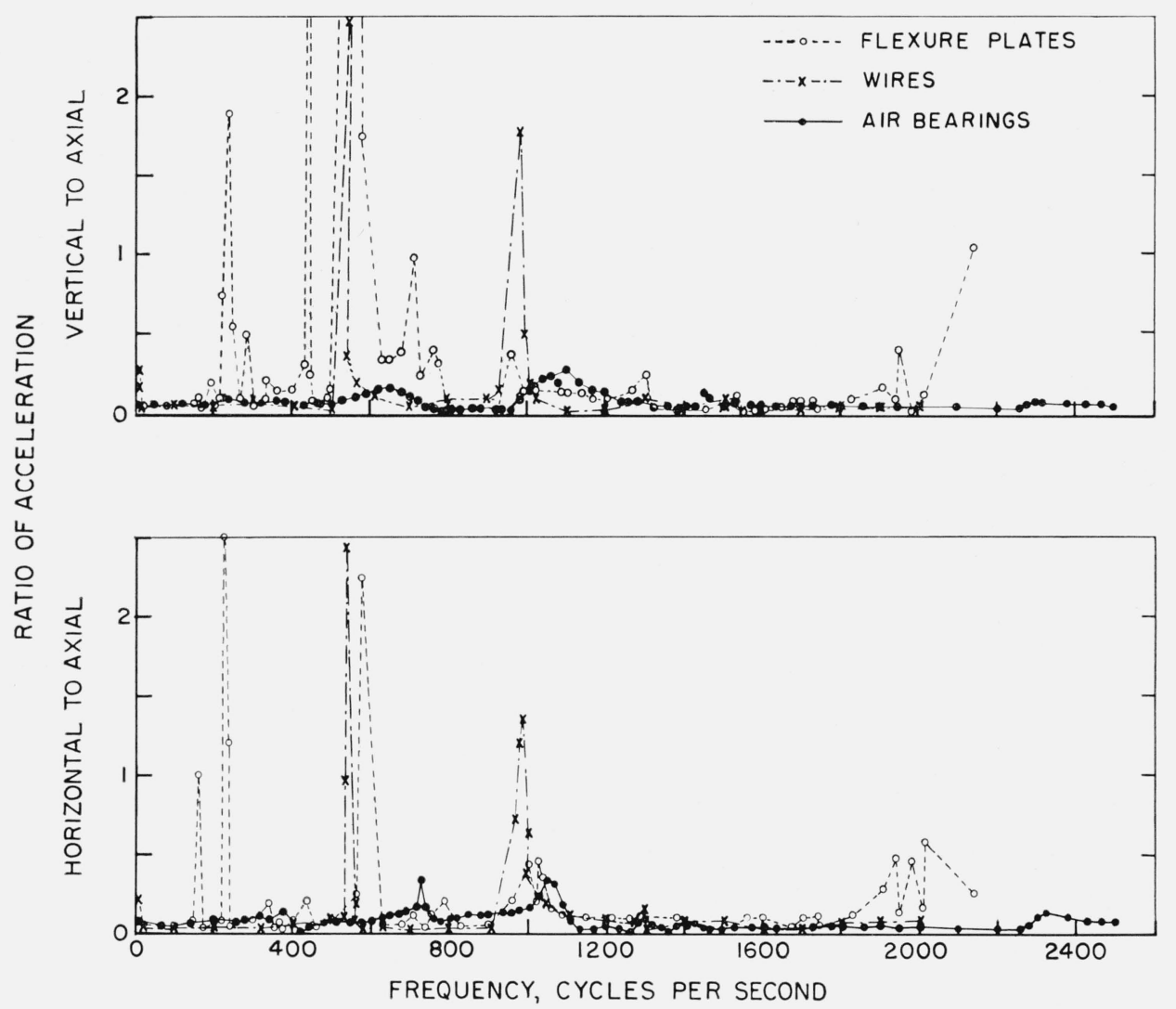

Figure 6. Measured accelerations due to transverse motions using three types of suspension systems.

fundamental and probably the second bending mode resonances of the moving element. In figure 6 the measured transverse motions of exciter No. 676 using air bearings (fig. 4) are compared with the transverse motions of exciter No. 619 using a flexure plate suspension and a tensioned wire suspension. Significant transverse motions of the air-bearing exciter in this case occur in the vertical direction at 650 and $1,100 \mathrm{c} / \mathrm{s}$ and in the horizontal direction at 730 and $1,050 \mathrm{c} / \mathrm{s}$. The differences between the transverse motions plotted here (fig. 6) and the transverse motions in the experimental set of bearings (fig. 5) are thought to be due to differences in bearing clearance and alinement.

\section{Calibration of the Air-Bearing Exciter}

The air-bearing exciter was calibrated by the reciprocity method. The results obtained by the use of the interferometer fringe disappearance and optical target methods are compared with the results of the reciprocity method.

The exciter rests on a concrete block isolated from floor-borne vibrations by compression coil springs.

\subsection{Reciprocity Calibration}

The reciprocity theorem for mechanical systems states that if a force is impressed at point $A$ and the velocity is measured at point $B$, the same velocity will be measured at point $A$ if the force is impressed at point $B$. The reciprocity theorem as applied to electrodynamic vibration exciters is given in reference [1]. In order for the theorem to hold, the system must be linear, i.e., the displacement, velocity and current must increase linearly with force and voltage. The application of reciprocity to this system is limited to frequencies above and below the resonances of the moving element. At frequencies near each resonance there is a loss in precision due to changes in the electromechanical properties of the calibrator in that the relationships are no longer linear.

The reciprocity calibration consists of two experiments: (1) measurement of transfer admittance between the driving coil and the velocity-sensing coil; (2) measurement of the voltage ratio of the open circuited velocity coil and driving coil when the exciter to be calibrated is driven by an external exciter.

Transfer admittance measurements, $\bar{Y}_{e}$, were made with a series of weights attached one at a time to the mounting table of the exciter. Also a zero load transfer admittance measurement was made before and after each measurement with a weight attached. The zero load transfer admittance is denoted by $\bar{Y}_{\mathrm{e} 0}$. The weights were increment weights ranging from $0.1 \mathrm{lb}$ to $2.0 \mathrm{lb}$. 
Using the measured values of $\bar{Y}_{e}$ and $\bar{Y}_{e 0}$, graphs of the real and imaginary values of the ratio $\frac{W_{(1,2 \ldots)}}{\bar{Y}_{e}-\bar{Y}_{e 0}}$ are plotted versus $W_{(1,2, \ldots)}$ for each frequency, where $W_{(1,2, \ldots)}=$ increments of mass attached to the table. The zero intercepts, $J$ and $i J$, of the resulting straight lines and their slopes, $Q$ and $i Q$, are computed by a weighted least square method.

Having determined the voltage ratio $\bar{R}, \bar{J}$, and $\bar{Q}$, the sensitivity of the exciter is given by

$$
\bar{S}=0.04288+0.04286 \frac{W \bar{Q}}{\bar{J}}(f \bar{R} \bar{J} \bar{j})^{1 / 2} \mathrm{v} / \mathrm{in} . / \mathrm{sec}
$$

where

$f$ is the frequency in cycles per second and $j$ is the unit imaginary vector.

\subsection{Interferometer Calibration}

The air-bearing exciter was calibrated by the interferometric fringe disappearance method as given in reference [8]. Figure 7 shows the exciter and interferometer in position for calibration. The sensitivity of the exciter is given by

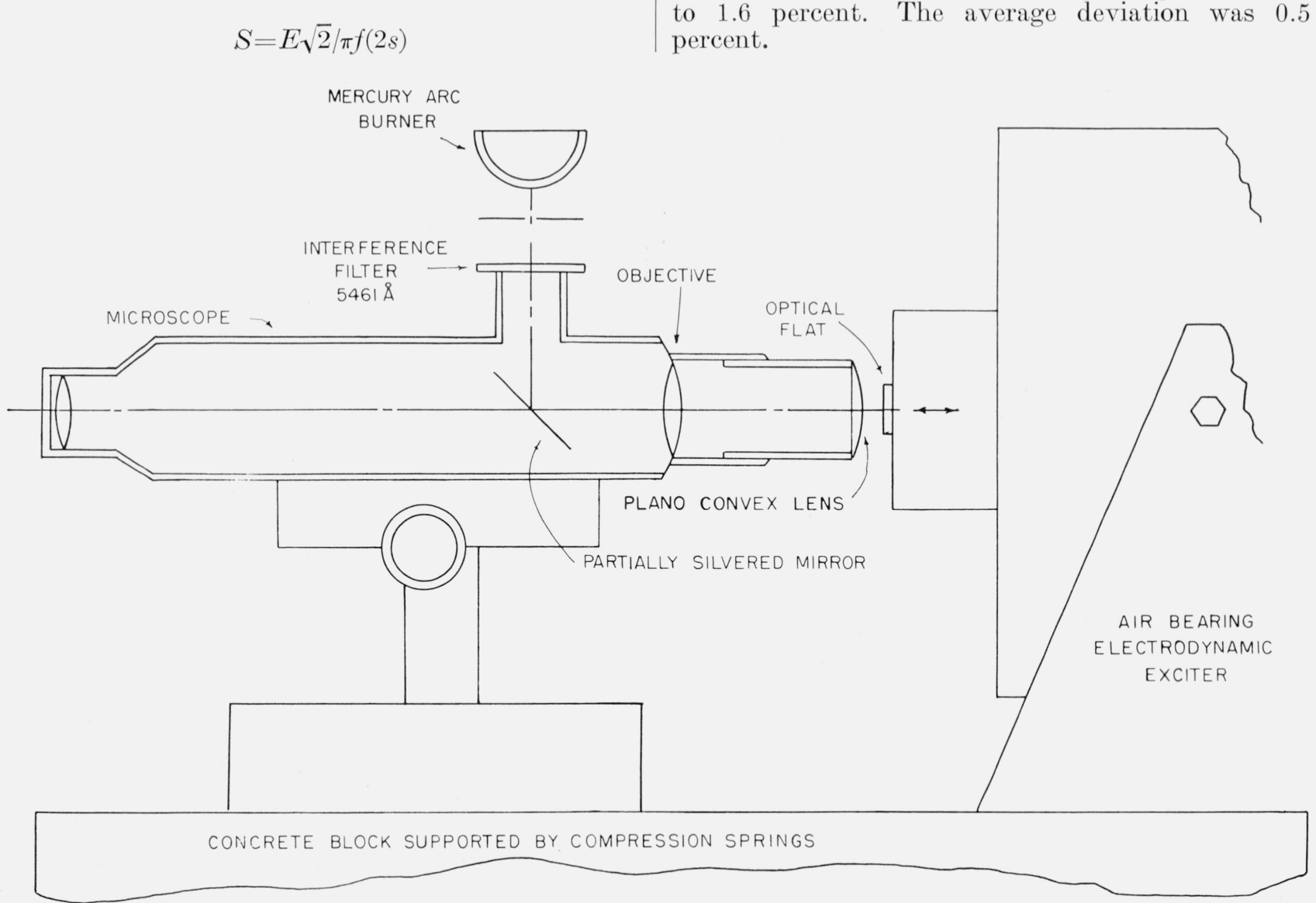

FIGURE 7. Schematic arrangement for calibration of exciter with interferometer. where $E$ is the rms voltage output of the velocity sensing coil corresponding to the first order fringe disappearance, $s$ is the amplitude of displacement of the moving element $\left(4.11 \times 10^{-6}\right.$ in. for the first order disappearance using mercury light and green filter), $f$ is the frequency, and $S$ is given in peak to peak $\mathrm{v} /$ in./sec. The voltage was read by an a-c transfer taken with the exciter in a horizontal position. Readings for zero load and $1 \mathrm{lb}$ load were taken over the range of 350 to $2,500 \mathrm{c} / \mathrm{s}$.

Each value of voltage, $E$, is obtained from the average of two observations, one for the first fringe disappearance during slowly increasing displacement amplitude and the second for the fringe disappearance during slowly decreasing amplitude. For the zero load, the mean deviation from the mean of the voltage values ranged from 0.1 to 0.7 percent. The deviations were computed from sets of six or more values at each test frequency over the range of 350 to $2,500 \mathrm{c} / \mathrm{s}$. The average deviation was 0.3 percent. The voltage values obtained by two observers differed from 0 to 0.8 percent for sets of three or more values per observer at each test frequency. The average repeatability was 0.3 percent.

For the $1 \mathrm{lb}$ load reading the reflecting glass was attached to the center of the weight. The mean deviation for the $1 \mathrm{lb}$ load readings ranged from 0.1 to 1.6 percent. The average deviation was 0.5 percent. standard using a VTVM as a null. The data were 
The use of the interferometer fringe disappearance method is greatly facilitated on the air-bearing exciter as compared to the tensioned wire exciter because of the increased stability of the interference fringes.

\subsection{Calibration With an Optical Target}

The air-bearing exciter was calibrated optically by small wire targets mounted on the exciter table. The targets were coated with particles from camphor smoke and the diameters measured to ten-thousandths of a centimeter. Two diameters of wires were used. A $0.2042 \mathrm{~cm}$ wire was used to calibrate at $15,17,20,30$, and $45 \mathrm{c} / \mathrm{s}$. A $0.1048 \mathrm{~cm}$ wire was used to calibrate at 55 and $70 \mathrm{c} / \mathrm{s}$. The exciter was driven with increasing amplitude until the wire appeared to vanish. The output of the velocity coil was used as the output corresponding to the amplitude of vibration given by the diameter of the wire. Knowing the amplitude, frequency, and output of the velocity coil, the sensitivity of the exciter was determined. The average sensitivity for 13 observations at 7 frequencies was $0.1859 \mathrm{v} / \mathrm{in}$. $/ \mathrm{sec}$ with a mean deviation of 0.0004 . This compares with an average of $0.1857 \mathrm{v} / \mathrm{in}$. $/ \mathrm{sec}$ for the reciprocity calibration from 10 to $400 \mathrm{c} / \mathrm{s}$ and 0.1857 volts/in./sec for the interferometer calibration from 350 to $750 \mathrm{c} / \mathrm{s}$.

Figure 8 shows the calibration factors obtained for the air-bearing exciter by the three methods described above.

\subsection{Calibration of Pickups}

After calibrations by the reciprocity method and the interference fringe disappearance method, vibration standard 676 with air-bearing supports was used to calibrate a piezoelectric acceleration pickup and an electrodynamic velocity pickup.

The piezoelectric pickup was calibrated by comparing its voltage output with the voltage generated by the velocity coil of the exciter. The sensitivity of the pickup is given by

$$
S_{\text {pickup }}=\frac{\text { voltage output of pickup }}{\text { voltage output of velocity coil }} S_{\text {exciter }}
$$

where the $S_{\text {exciter }}$ is corrected to read $\mathrm{v} / \mathrm{g}$ instead of $\mathrm{v} / \mathrm{in} . / \mathrm{sec}\left(\mathrm{g}=386 \mathrm{in} . / \mathrm{sec}^{2}\right)$. This ratio is determined by the following transfer admittance ratios:

$$
\frac{I_{\text {driving coil }} / V_{\text {velocity coil }}}{I_{\text {driving coil }} / V_{\text {pickup }}}=\frac{V_{\text {piekup }}}{V_{\text {velocity coil }}} .
$$

The electrodynamic velocity pickup was calibrated similarly. The results of these calibrations are given in figures 9 and 10 .
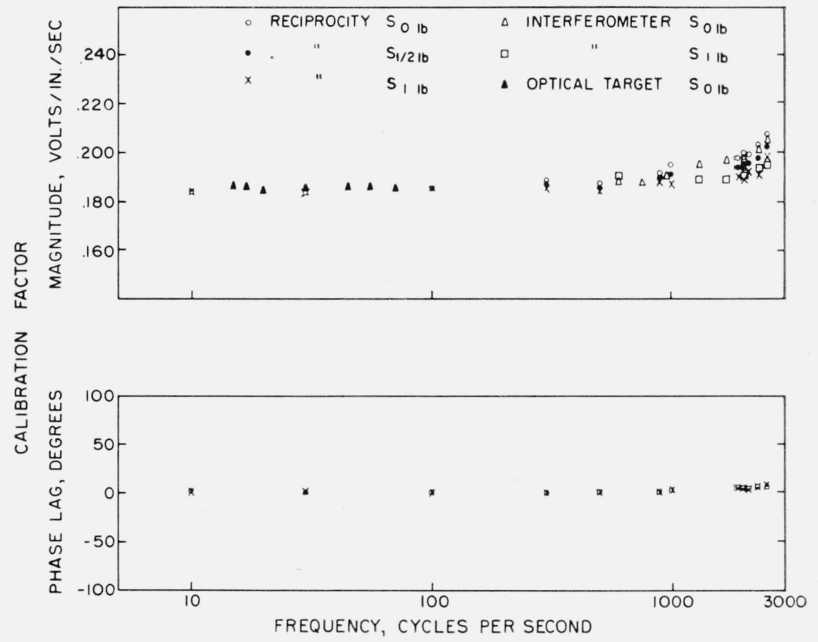

FiguRE 8. Calibration factors of the exciter velocity sensing coil.

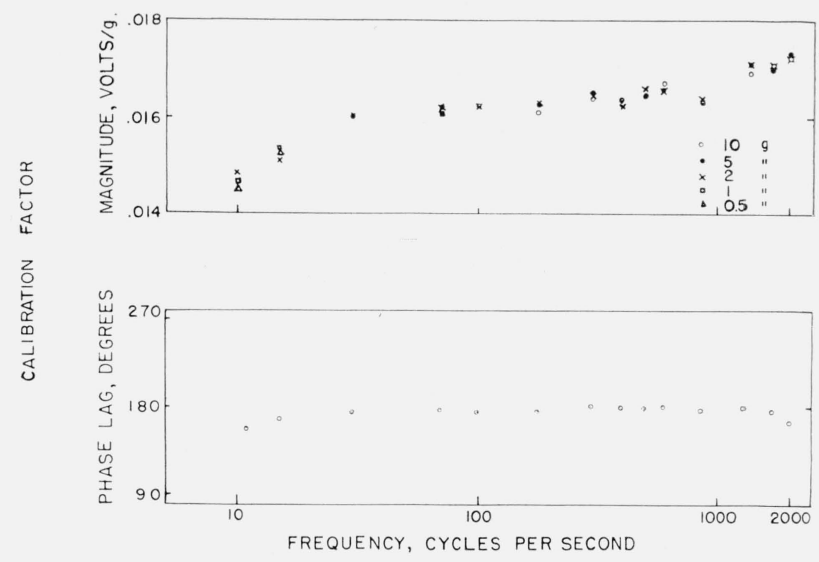

Figure 9. Calibration factors of a piezoelectric acceleration pickup.
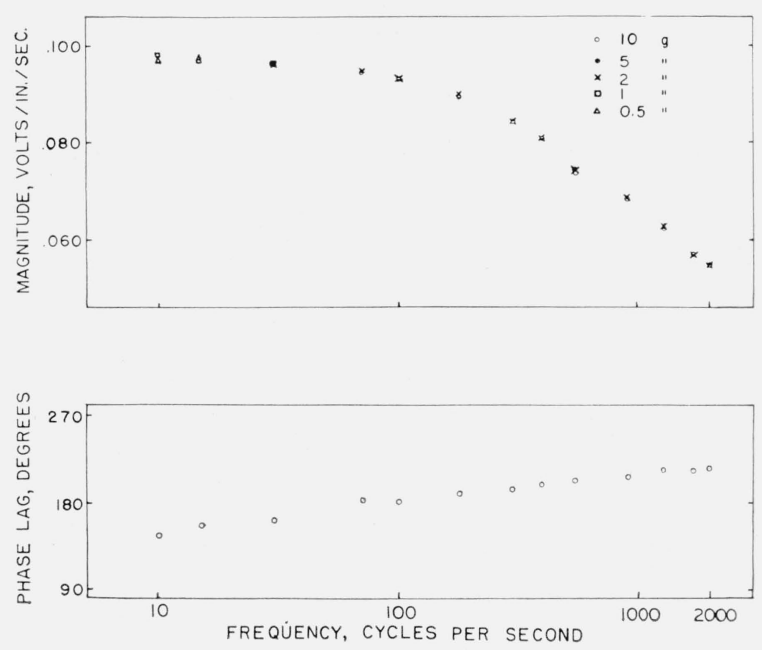

Figure 10. Calibration factors of an electrodynamic velocity pickup. 


\section{Discussion}

Although the air-bearing suspension resulted in eliminating much of the transverse motion for exciter 676 (see fig. 6), there are still frequencies near 700 and $1,000 \mathrm{c} / \mathrm{s}$ which should be avoided during calibrations of vibration pickups.

It is extremely unlikely that five of the six degrees of freedom of the mounting table can be eliminated due to the geometrical configuration of the moving element as shown schematically in figure 1. Also, there are several materials with different moduli of elasticity incorporated into the moving element. Due to these factors, axial and flexural resonances may be excited in the moving element that interfere with its use as a pickup calibrator.

It is attractive to consider the possibility of constructing moving elements of uniform cross section and maximum axial and transverse stiffnesses. Such elements should be much better for use in vibration standards.

Certain advantages accrue from the substitution of the air-bearing suspension guidance system for flexure plates and tensioned wires. The air bearings allow larger axial motions than were possible with the mechanical suspension systems. The flexure plates and wires themselves were excited in resonance at certain frequencies which interfered with the utility of the exciter. With air bearings, the moving element is free to move axially but is prevented from moving laterally; this minimizes transverse motions at the mounting table.
Richard Harwell machined the bearings and supporting assembly. Ruth M. Woolley performed most of the computations. James A. Miller and L. R. Sweetman rendered valuable assistance and constructive criticism.

\section{References}

[1] Samuel Levy and Raymond R. Bouche, Calibration of vibration pickups by the reciprocity method, J. Research NBS 5\%, 227-243 (1956) RP2714.

[2] R. R. Bouche, Improved standard for the calibration of vibration pickups, Proc. SESA, XVIII No. 1, 116-121 (1961).

[3] Anon., Calibration of shock and vibration pickups, ASA S2.2-1959.

[4] H. L. Wunsch, Design data for flat air bearing when operating under steady conditions of load, The Mechanical Engineering Research Laboratory, East Kilbride, Glasgow; reprint from Machinery, 93, No. 2394, 765-775'(Oct. 1, 1958).

[5] S. K. Grinnel and H. H. Richardson, Design study of a hydrostatic gas bearing with inherent orifice compensation, Trans. ASME 79 (1957).

[6] J. H. Laub, Gas lubrication in instruments and control devices, National Aeronautics and Space Administration-Jet Propulsion Laboratory, Technical Release No. 34-169 (Nov. 10, 1960).

[7] P. H. Stahlhuth, Hydride gas bearings for better stability, Product Eng. (April 10, 1961).

[8] S. Edelman, E. Jones, and E. R. Smith, Some developments in vibration measurement, J. Acoust. Soc. Am. 2\%, No. 4, 728-734 (July 1955).

[9] C. M. Harris and C. E. Crede, Shock and Vibration Handbook (McGraw-Hill Book Co., Inc., New York, 1961).

(Paper 67C4=144) 